\title{
Early onset of diabetic nephropathy
}

\author{
J Francis, S J Rose, F Raafat, D V Milford
}

\begin{abstract}
A 12 year old Asian girl with a four year history of poorly controlled insulin dependent diabetes mellitus developed overt diabetic nephropathy. There were no clinical features of Rabson-Mendenhall syndrome. Screening for microalbuminuria would have identified incipient diabetic nephropathy and highlighted the importance of good glycaemic control. Although screening for microalbuminuria is recommended after five years from diagnosis, it may be appropriate to undertake this annually in those with poor glycaemic control.

(Arch Dis Child 1997;77:524-525)
\end{abstract}

Keywords: diabetic nephropathy; adolescent; microalbuminuria; hypertension

Birmingham

Children's Hospital,

Ladywood Middleway,

Birmingham B16 8ET:

Department of

Nephrology

J Francis

D V Milford

Department of

Pathology

F Raafat

Department of

Paediatrics,

Birmingham

Heartlands Hospital

S J Rose

Correspondence to:

Dr Milford.

Diabetic nephropathy is rare in adolescents and unusual in those who have been diagnosed for less than five years. However, microalbuminuria (incipient nephropathy) and even renal histological changes can be found a relatively short while after diagnosis in some diabetics. It is not clear what determines the rate of progression from incipient to overt nephropathy but hypertension, glomerular hyperfiltration, hypercholesterolaemia, and poor glycaemic control have been implicated. ${ }^{1}$ We describe a case of rapid onset overt nephropathy in a diabetic with poor glycaemic control.

\section{Case report}

A previously healthy 8 year old girl born of a consanguineous Asian marriage presented in

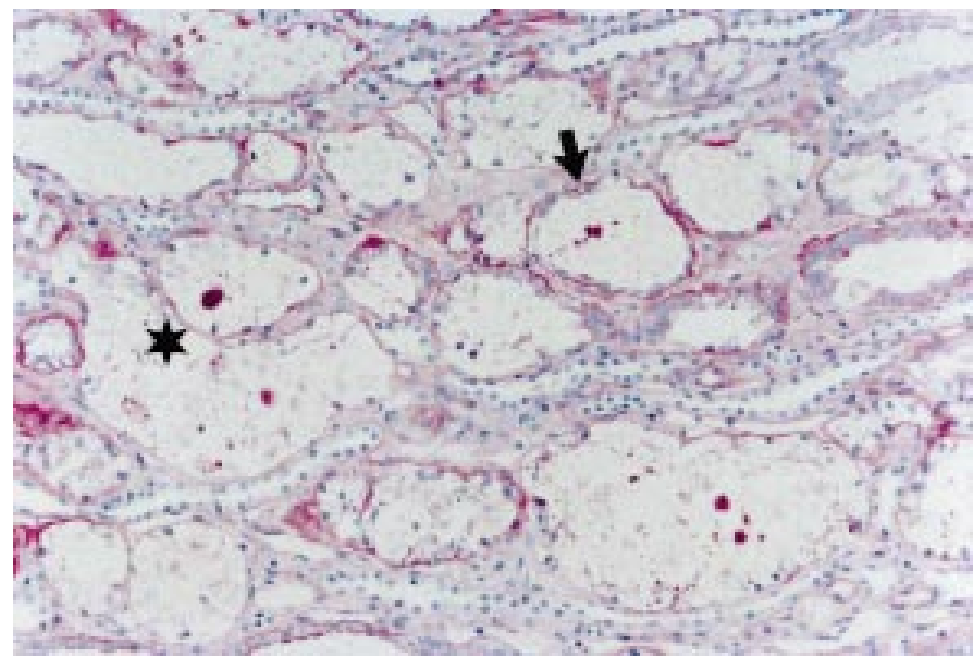

Figure 1 Periodic acid Schiff stain (magnification $\times 20$ ) demonstrating wrinkled tubular basement membranes (arrow) and marked vacuolation of tubular cells due to glycogen deposition (Armanni-Ebstein lesion ${ }^{\star}$ ).
1992 with a one month history of polyuria, polydipsia, and weight loss with a blood glucose of $19.7 \mathrm{mmol} / 1$ and a glycated haemoglobin of $7.5 \%$. Insulin dependent diabetes mellitus was diagnosed and she was commenced on Humulin M3 (Lilly) 1.0 units $/ \mathrm{kg} /$ day. Her mother was reported to have uncomplicated non-insulin dependent diabetes mellitus. Education of the child and family proved to be difficult despite the use of interpreters and subsequent compliance with the insulin regimen and diet was poor. Extremes of blood glucose were evident because of frequent hypoglycaemic attacks and episodes of diabetic ketoacidosis over the subsequent years. Glycated haemoglobin values $\left(\mathrm{HbA}_{1 \mathrm{c}}\right)$ were consistently high, the mean value being $12 \%$ (range $5-15.5 \%$, normal range 3.5$7 \%$ ) over this time. By four years from diagnosis the insulin requirement had increased to 1.3 units/kg/day, although diabetic control remained poor. She was noted to be hypertensive and to have heavy proteinuria. An ophthalmic examination revealed oedema of both retinas and some peripheral vessels with features suggestive of early neovascularisation.

After referral to this hospital hypertension was confirmed by 24 hour ambulatory blood pressure monitoring (30\% of systolic and $70 \%$ of diastolic blood pressure readings greater than 97.5 centile for height). She was hypercholesterolaemic (cholesterol $5.8 \mathrm{mmol} / \mathrm{l}$ ). The early morning urine protein to creatinine ratio was significantly raised at $483 \mathrm{mg} / \mathrm{mmol}$ (normal less than 20, nephrotic range greater than 200) but plasma albumin was normal at $40 \mathrm{~g} / \mathrm{l}$. Plasma creatinine was $36 \mu \mathrm{mol} / 1$ giving a calculated glomerular filtration rate of 164 $\mathrm{ml} / \mathrm{min} / 1.73 \mathrm{~m}^{2}$ using the Schwartz formula.

A renal biopsy specimen demonstrated striking tubular epithelial cell vacuolation due to glycogen deposits (Armanni-Ebstein lesion, fig 1), early nodular glomerular sclerosis, hyaline deposits in the tubules, thickened tubular basement membrane, and arteriolar sclerosis. Immunofluorescence demonstrated IgG in capillary walls and Bowman's capsule.

On electron microscopy (fig 2) there was marked thickening and irregularity of the basement membrane of the capillary wall. The lamina densa was thickened and irregular and lamellation of the lamina rare was noted.

\section{Discussion}

The finding of heavy proteinuria, hypertension, and a raised glomerular filtration rate were indicative of overt diabetic nephropathy, a clinical state not normally entered before 15-20 years of diabetes. The renal biopsy findings were typical of diabetic glomerulopathy; 




Figure 2 Gross thickening of the glomerular basement membrane demonstrated on electron microscopy (magnification $\times 9900)$.

the marked vacuolation due to glycogen deposition was unusual and caused by very poor glycaemic control. Our review of the literature has identified only one prepubertal child who developed diabetic nephropathy 4 years 9 months after the onset of diabetes but in contrast to our case there was a family history of diabetic nephropathy. ${ }^{2}$

Such a presentation with overt diabetic nephropathy so soon after the onset of diabetes is unusual. The early onset of insulin dependent diabetes is said to be associated with the later development of proteinuria and it has been suggested that the progression of nephropathy in childhood may be slower than in later life. ${ }^{3}$ By contrast one study suggested the incidence of incipient and overt nephropathy in adolescent diabetics may be greater than previously thought, ${ }^{4}$ although the minimum duration of disease in this study was five years.

It is unclear why some individuals develop diabetic nephropathy at an earlier stage than others, ${ }^{1}$ although poor compliance with the treatment regimen is the likely explanation in this case. Poor glycaemic control is a well recognised risk factor for the development of renal vascular disease. ${ }^{5}$ The genetic factors contributing to the development of nephropathy are unclear but a role is suggested from the finding that patients with diabetic nephropathy and their first degree relatives have abnormal erythrocyte $\mathrm{Na}^{+} / \mathrm{Li}^{+}$countertransport, possibly predisposing them to hypertension. Moreover, the recent observation that advanced glycosylation end products increase mesangial cell transforming growth factor- $\beta$ and platelet derived growth factor production with a result- ant increase in collagen III synthesis ${ }^{6}$ suggests these cytokines may have a part to play in the development of renal lesions and this propensity may well be found to vary between individuals. Ethnic influences have been noted with a high incidence of diabetic nephropathy in Asians and other populations.

While most individuals with persistent microalbuminuria go on to develop overt nephropathy, good glycaemic control may prevent or slow progression, although hypertension, hyperlipidaemia, and ethnicity may also influence the rate of progression. Biopsy changes of nephropathy have been noted early in the course of diabetes and histological assessment may serve to identify children who would benefit from intensive efforts to achieve good glycaemic control. In contrast evidence suggests the clinical course of individuals with heavy proteinuria cannot be altered by good glycaemic control but reduction of hyperlipidaemia and the use of angiotensin converting enzyme inhibitors to control blood pressure and reduce proteinuria may diminish the rate of decline in renal function.

This case demonstrates early onset diabetic nephropathy in an Asian child without a strong family history of diabetic nephropathy. Regular screening for microalbuminuria is not usually undertaken before five years from diagnosis but could be justified in those with poor glycaemic control. In this child the finding of microalbuminuria may have identified the earlier need for renal biopsy to detect structural renal changes and would have served to reinforce the clinical drive to improve glycaemic control, possibly slowing the development of overt diabetic nephropathy. Unfortunately, better glycaemic control alone is now unlikely to alter her clinical course but aggressive management of hyperlipidaemia and control of blood pressure using an angiotensin converting enzyme inhibitor may reduce the rate of decline in renal function.

1 Campbell FM. Microalbuminuria and nephropathy in insulin dependent diabetes mellitus. Arch Dis Child 1995;73:4-

2 DeClue TJ, Campos A. Diabetic nephropathy in a prepubertal diabetic female. $\mathcal{F}$ Pediatr Endocrinol 1994;7: 43-6.

3 Shield JP, Hunt LP, Karachaliou F, Karavanaki K, Baum JD. Is microalbuminuria progressive? Arch Dis Child 1995;73: 512-4.

4 Quattrin T, Waz WR, Duffy LC, et al. Microalbuminuria in an adolescent cohort with insulin-dependent diabetes mellitus. Clin Pediatr (Phila) 1995;34:12-7.

5 Coonrod BA, Lloyd CE, Ellis D, et al. Predictors of microalbuminuria in individuals with IDDM. Pittsburgh epidemiology of diabetes complications study. Diabetes Care miology of diabe

6 Throckmorton DC, Brogden AP, Min B, Rasmussen H, Kashgarian $M$. PDGF and TGF- $\beta$ mediate collagen production by mesangial cells exposed to advanced production by mesangial cells exposed to advan
glycosylation end products. Kidney Int 1995;48:111-7. 